\title{
Risk Preference, Health Risk Perception, and Environmental Exposure Nexus: Evidence from Rural Women as Pig Breeders, China
}

\author{
Ruishi $\mathrm{Si}^{1} \cdot$ Xueqian Zhang ${ }^{1} \cdot$ Yumeng Yao ${ }^{1} \cdot$ Qian $\mathrm{Lu}^{2}{ }^{\mathbb{D}}$ \\ Accepted: 19 October 2021 / Published online: 29 October 2021 \\ (C) The Author(s), under exclusive licence to Springer Nature B.V. 2021
}

\begin{abstract}
Rural women are an integral part of the agricultural economy. Still, their exposure to environmental pollution, especially in the context of risk preference and health risk perception, has not gained much attention in the existing literature. So to explore this notion, a survey and experimental data of 714 rural Chinese women as pig breeders are taken, we innovatively evaluate the degree of environmental exposure from the pre-exposure, in-exposure, post-exposure intervention of women breeders, and two-stage least squares (2SLS) method is employed to address the endogeneity issue between health risk perception and environmental exposure. The results show that rural women breeders suffer from severe environmental exposure, and the degree of environmental exposure is up to $72.102(\operatorname{Min}=0, \operatorname{Max}=100)$. Risk preference also emerges as a crucial determinant behind their environmental exposure, but health risk perception significantly deters the degree of environmental exposure. The health risk perception can offset risk preference effects on women breeders' environmental exposure by $15.15 \%$. Moreover, considering the heterogeneity of the breeding scale, it is found that the impact of risk preference and health risk perception on women breeders' environmental exposure is an inverted U-shaped relationship, i.e., the results are at the turning stage when the breeding scale is $31-40$ heads. Based on the empirical findings, the study offers guidelines for policymakers to enhance awareness amongst women breeders regarding health and pollution and encourage them to opt for environment-friendly breeding. Moreover, this research also has substantial guiding significance for related research on environmental exposure of rural women in other developing countries.
\end{abstract}

Keywords Risk preference $\cdot$ Health risk perception $\cdot$ Environmental exposure $\cdot$ Women breeders $\cdot$ Experimental economics $\cdot 2$ SLS

Qian Lu

luqian110203@163.com

School of Public Administration, Xi'an University of Architecture and Technology, Xi'an, China

2 College of Economics and Management, Northwest A\&F University, Yangling, China 


\section{Introduction}

\subsection{Health Damage and Governance Dilemma of LPM Pollution}

In developing countries, the undisposed harmlessly livestock and poultry manure (LPM) generally contributes to a large amount of greenhouse gas emissions such as $\mathrm{CH}_{4}$ and $\mathrm{N}_{2} \mathrm{O}$ (Adegbeye et al., 2019; Post et al., 2020), sewage embodying urine and flushing water (Herrero et al., 2015; Leip et al., 2015), coupled with bacteria such as Escherichia coli and Salmonella (Więckol-Ryk et al., 2020), and viruses like African swine fever and pandemic influenza (Jurado et al., 2018) and eventually poses a severe threat to human health especially in rural areas (Sun et al., 2015). It is estimated that China's LPM production was around 4 billion tons in 2020. Still, the probability of harmless disposal or recycling, such as composting and fermentation, is less than $60 \%$, and the total amount of undisposed LPM is as high as 160 million tons (Xu et al., 2020). Moreover, the drastically reduced farmland and farmers' livelihood transformation limits the proper and efficient application of LPM as organic fertilizer, which further limits the LPM's harmless disposal or recycling (Dong et al., 2020; Haase et al., 2017). Over the past 30 years, a rich body of literature is focusing on the carbon emissions reductions arising from LPM to cope with environmental pollution (Ali et al., 2020; Won et al., 2020), such as adopting harmless disposal technologies (Jeswani et al., 2019), and boosting recycling efficiency (Lonappan et al., 2016; Won et al., 2020). But in the context of human health, only a few studies paid attention to the health damage caused by LPM pollution (Andersen et al., 2012; Beek, 2010). In the existing literature, the studies in medicine are mainly based on theoretical and statistical analysis to deduce whether the LPM pollution negatively influences breeders' health or not. But empirical analysis of causal effects between LPM pollution and physical or mental health in context of economics is challenging that requires a long-term randomized controlled trial. The impact of other omitted variables such as age growth on health damage is also noticeable.

\subsection{Reducing Environmental Exposure as Feasible Paths to Cut Off the Causal Relationship Between LPM Pollution and Breeders' Health Damage}

Some scholars believe that LPM pollution causes damage to breeders' health, mainly human brain impairment (Cai et al., 2018; Zhang et al., 2018). Moreover, breeders have to work for a long time in environments comprised of feed dust, ammonia, and fecal bacteria arisen from manure, so they suffer from many other health problems such as coughing, fever, and shivering (Bontems \& Thomas, 2006). Additionally, breeders' mental health is more susceptible to animal epidemics, production losses, as well as experiencing sudden deaths of livestock (Cai et al., 2018; Neethirajan, 2020). However, other scholars argued that mechanization, standardization, and large-scale breeding had brought significant improvements in the environment and manure recycling (Hoffmann et al., 2009). So now, the breeder's health is less likely to be affected by the LPM (Neethirajan, 2020; Yilmaz et al., 2013). Moreover, the present studies mainly explored the effect of LPM pollution on direct individuals' health instead of potential influencers, which are difficult to observe and evaluate. Academia generally considered that the reason for the above dispute may be the ignorance of breeders' heterogeneous degree of environmental exposure, as discussed by Wild (2005) and 
Zhang et al. (2018) in their study stated that environmental exposure is a necessary path for the causal relationship between environmental pollution and health damage. When environmental pollution achieves natural purification or within the scope of people's tolerance, that is, the degree of people's environmental exposure is relatively low, health damage is minimal; when people are exposed to severe environmental pollution, it is inferred that health damage is inevitable. Therefore, academia generally believes that there are two notions concerning the cut off between the potential causal effects of environmental pollution and health damage: the first is to eliminate environmental pollution through the sustainable green production model; the second is to reduce environmental exposure when environmental pollution cannot be eliminated entirely (Post et al., 2020; Zhou et al., 2020). Unfortunately, adopting a green sustainable development model requires reconfiguring production factors and industrial transformation and upgrading, which still requires gradual progress for developing countries.

The concept of "exposure" formerly originated from a few occupational diseases and epidemics, which generally act as an intermediary between risk factors and resultant health effects as doctors are more susceptible to viruses exposure (Rappaport, 2011). So the "exposure" is different from the risk and is considered as an interaction effect of individuals' intervention and risk factors (Sogno et al., 2020). There are three broad exposure categories-internal (e.g., hormones, microflora), specific external (e.g., infectious disease, toxicants), and general external (e.g., social, psychological) (Santos et al., 2020). In recent years, much attention has been given to environmental issues. In this pursuit, the new concept of "environmental exposure" has also been developed and already applied in many fields such as medicine, transportation, urban geography, and urban planning (Poom et al., 2021). For instance, obesity, respiratory diseases, and various clinical illnesses have provoked the association of environmental exposure and its effects on residents' health (Sugiyama et al., 2018). Moreover, exposure to stressors such as bad air or water quality, noise, extreme heat, or an overall unnatural surrounding may endure the susceptibility to non-communicable diseases (Sogno et al., 2020). Besides, exposure to environmental factors such as green and blue environments, meteorological factors, noise, and air pollution has also been proven to impact residents' mental health directly (Boers et al., 2018; Dzhambov et al., 2018). Based on the above discussion, it is apparent that the existing studies focused on the assumption that environmental exposure significantly reduces individuals' health welfare. In fact, in addition to unobservable environmental risks, individuals may take positive or feasible actions to reduce health risks of environmental exposure through pre-exposure, in-exposure, and post-exposure interventions (Dai et al., 2020; Oskar $\&$ Stingone, 2020). Owing to the significant differences of individuals' risk management, results for environmental exposure may be significantly heterogeneous; that is, environmental exposure in the causal relationship between environmental pollution and health outcomes shows a mediation and threshold effect (Buck Louis et al., 2013; Shaffer et al., 2017). So academia generally argues that "environmental exposure" may provide another innovative path to solve this problem instead of how to implement a sustainable green production model and finally eradicate environmental pollution. In this regard, it is more advantageous to evaluate the degree of environmental exposure, analyze possible influencing factors, and explore the driving mechanism and countermeasures to reduce environmental exposure and effectively cut off the possible causal relationship between environmental pollution and breeders' health. The above discussion is conceptualized as below in Fig. 1. 


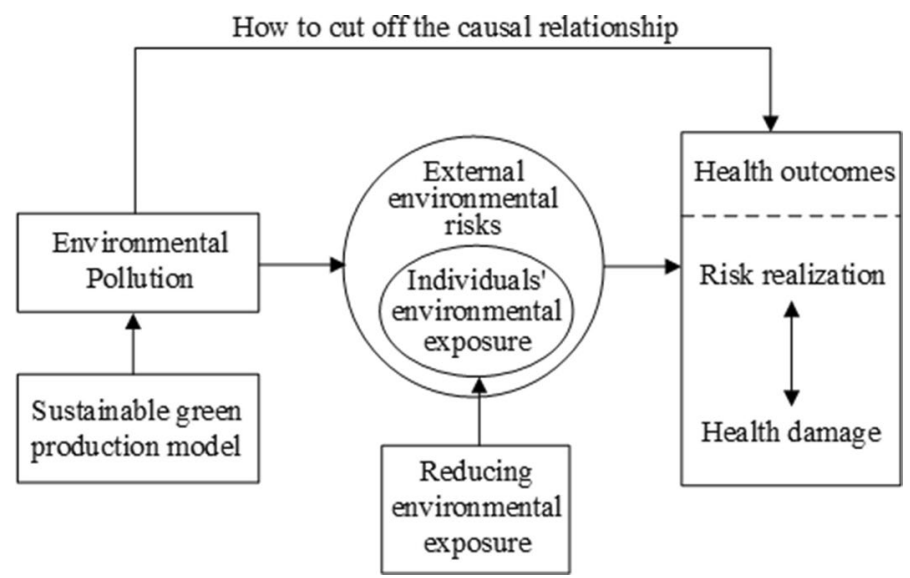

Fig. 1 Paths to remove the causal relationship between LPM pollution and health damage

\subsection{Theoretical Analysis of Risk Preference, Health Risk Perceptions, and Women Breeders' Environmental Exposure}

The pig breeders dealing with LPM are confronting with a series of environmental risk factors such as sewage, bacteria, viruses, and malodor (Dong et al., 2020). As discussed before, the degree of environmental exposure mainly describes the interactive results of breeders' intervention in response to environmental risk factors, which can also be considered as breeders' decision-making behaviour regarding risk. According to prospect theory, individuals' risk decision-making behavior is jointly determined by risk preference and subjective judgment for the probability of risk realization characterized by risk damage (Kahneman \& Tversky, 1979). Risk preference is divided by risk-aversion, risk-neutrality, and risk-taking, and individuals' judgment for the probability of risk realization is represented by risk perception (Bo \& Sterken, 2007). Thus, risk preference and risk perception are closely related to breeders' decision-making behavior regarding a series of risks. In particular, risk preference is an individual's attitude or persistent tendency towards risk factors (Elwell, 2009). Roumasset (1976) and Scott (1997) stated that farmers in developing countries are generally risk-aversion. Lence (2009) considers that due to incomplete information, the risk aversion attitude has significantly affected farmers' adoption of agricultural technology, implementation of protection measures, and investment of related funds. Qiu et al.(2014) believed that the higher risk aversion farmers are, the more inclined they are to over-apply chemical fertilizers. Zhu et al. (2016) argued that although new agricultural technologies or measures brought about specific risks, there are still significant differences in the willingness to adopt the technology by different farmers with risk-aversion, risk-neutrality, and risk-taking. However, other scholars considered that the classification criteria of risk preference are unclear and not strict. It is reasonable to employ an experimental economics method to measure the degree of risk preference(Duan et al., 2021; Nie et al., 2021).

Besides, scholars have also focused on the role of risk perception. Risk perception describes individuals' risk judgment on uncertainty and damage consequences (Slovic, 1987). Risk perception directly affects farmers' risk decisions (Kahneman \& Tversky, 1984). The stronger the farmers' risk perception, the more likely they take risk 
resistance behaviors (Weber \& Milliman, 1997). Botzen et al.(2009) believed that the stronger the individual perceives flood risk, the more willing they are to buy sandbags to avoid risks. Bryan and Kandulu (2011) also stated that public health risk awareness has a positive and significant influence on farmers' participation in manure waste management. Si et al. (2020) believed that health risk perception exerts a positive and statistically influence on farmers' recycling behavior of carcass waste. Besides, some scholars also argued that, due to the heterogeneity of risk preference and risk perception, there is a crossed association between risk preference and risk perception, affecting individual risk decision-making behavior such as purchasing insurance and adopting conservation tillage (Lopes, 1986; Turvey et al., 2012). However, other scholars believe that the combined effects of risk-aversion, risk-neutrality, and risk-taking, as well as high-risk perception and low-risk perception, can be verified in theory. Still, actually, it is difficult to be observed and tested(Qiu et al., 2020a, 2020b). Consequently, we mainly measure the degree of risk preference and risk perception and further discuss the parallel effects of risk preference and risk perception.

Furthermore, in China, farmland transfer arouses surplus rural laborers, and the men urban-rural migration work has become the main labor distribution in rural families (Cao et al., 2020; Zhang et al., 2020; Si et al. 2020). Coupled with the demand for caring for the elderly and nurturing children, the women had also taken the responsibility of breeding livestock and poultry to subsidize the family income (Song et al., 2020). Given the small farming scale, the low proportion of green breeding, and insufficient disposal manure, many rural women are exposed to LPM pollution (Kuhn et al., 2020). Although the government requires breeders to implement green livestock and poultry rearing model through the rural revitalization strategy, it still takes a long time due to insufficient capital input. Moreover, although the government has established gender equality in legislation and granted women land rights; still women's rights concerns regarding their health, the voice for their rights are not supported and even taken for granted. Additionally, women in China residing in deprived rural areas have low health risk perceptions, putting their health conditions incredibly at worst for a long time ( $\mathrm{Li}$ et al., 2020). Although some scholars have discussed rural women's cognitive health (Ginja et al., 2020), nutritional status (Perkins et al., 2019), pregnant women's health rights (Bussink-Voorend et al., 2020), and food insecurity issues (Sinclair et al., 2019), as well as cooking fuels impacting women's health (Imran \& Ozcatalbas, 2020) in the existing studies. But as far as rural women breeders' environmental exposure is concerned, to our knowledge, no research is conducted before, which must be addressed on a prior basis.

So keeping in view the above discussion, our research contributes to the existing literature in four ways. Firstly, according to prospect theory, risk preference and health risk perceptions are incorporated into the unified framework for exploring the environmental exposure faced by women pig breeders in rural areas. Secondly, this research initially used exploratory factor analysis to measure the degree of environmental exposure from breeders' pre-exposure, in-exposure, and post-exposure interventions. Thirdly, based on the survey data of 714 rural women as pig breeders, we employed the 2SLS to address the endogeneity issue between health risk perception and environmental exposure and attempted to examine the effects of risk preference and health risk perception on women breeders' environmental exposure. Finally, according to the research conclusions, some targeted suggestions are put forth to reduce rural women's environmental exposure and gradually improve their health status. The research framework is shown in Fig. 2. 


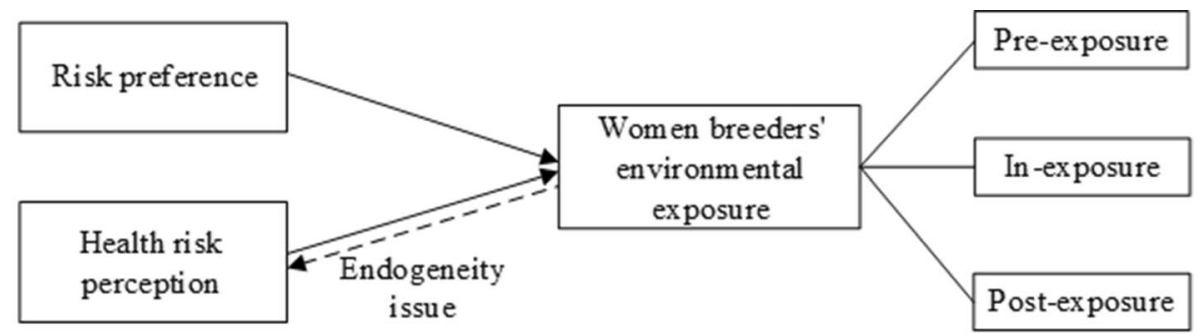

Fig. 2 Research framework of this paper

\section{Materials and Methods}

\subsection{Study Area and Sample Collection}

Based on the first survey conducted in 2018, the field survey was again carried out in nine counties of three provinces of China, i.e., Hebei, Henan, and Hubei provinces, from April 15th to May 10th, 2019 (see Fig. 3). The main reasons behind choosing these sample areas are their intensive engagement in pig rearing, which has become a backbone for boosting the agricultural economy of those areas. In 2018, the slaughtering numbers of pigs in Hebei, Henan, and Hubei were 30.04 million, 54.28 million, and 36.14 million, accounting for 4.33, 7.83, and 5.21 percent of the total number of slaughtered pigs in China (National Bureau of Statistics of China, 2019). According to the report of governmental

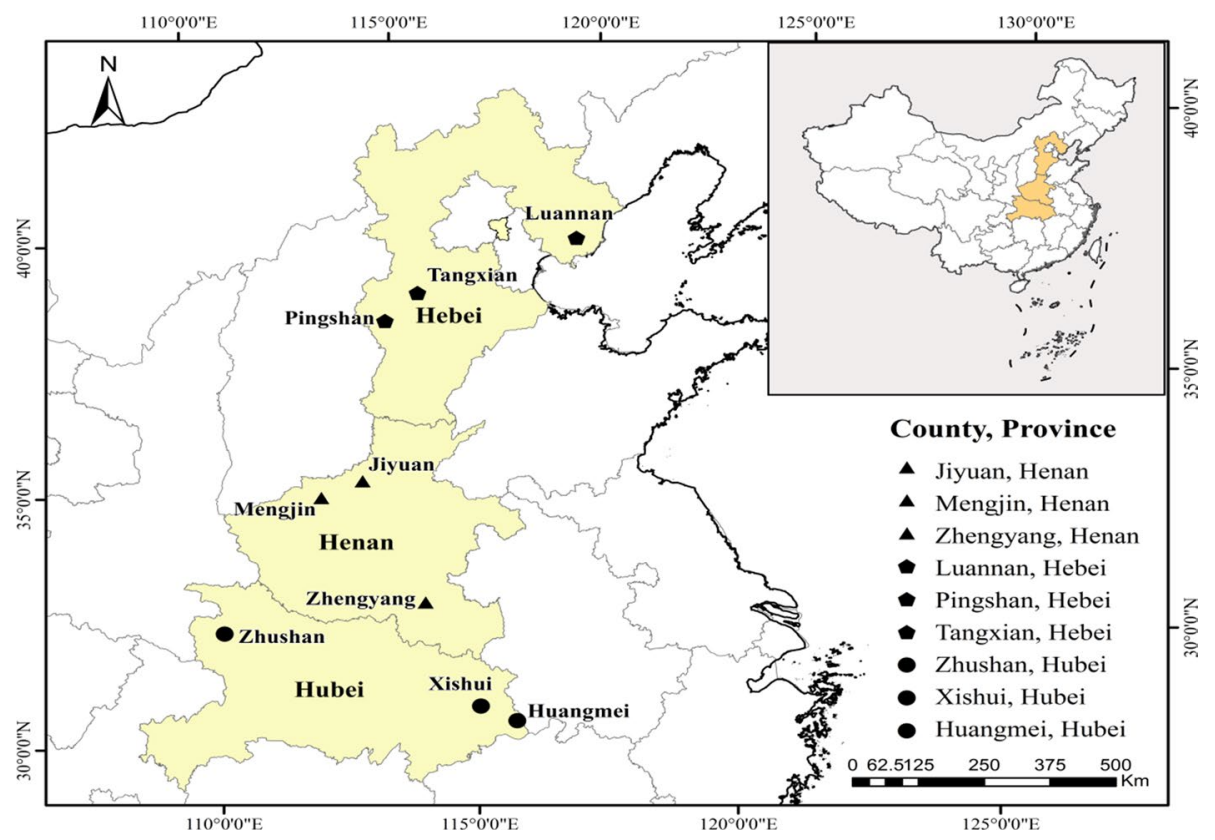

Fig. 3 Sample distribution area ( Source: Arc GIS 10) 
environmental supervision and inspection in 2018, it is documented that the proportion of pig rearing coupled with agricultural farming in these areas is only $13.50 \%$, and the degree of standardized breeding is $35.15 \%$. Moreover, the harmless disposal or recycling degree of the LPM is less than 50\% (Wang et al., 2019). Hence, it is proven that the ecological environment in sample areas is seriously polluted by manure, so this survey area is an excellent representative to meet the desired objective of the study.

By following the sampling methods proposed by Kahneman and Tversky (1979) and Sharifzadeh et al. (2019), the research team also employed stratified and random sampling methods. Randomly 3-5 townships from each sample county were selected; from each township, 4-6 villages were randomly selected, and in the last stage, pig breeders from the villages were also randomly selected. The questionnaires were used to gather the data, and additionally, the research team also interviewed the heads of livestock departments. A total of 40 interview records comprised of a detailed grasp of the pig industry development, environmental manure pollution, environmental regulations, etc., in the sample areas were obtained. The questionnaire content mainly comprised the interviewees' characteristics, family and business characteristics, geographical, environmental conditions, risk perception, protective measures response to manure pollution, and government regulations. Before the formal survey, the research team conducted a pre-survey in Pingshan County, Hebei, and revised the questionnaire's content. A total of 800 questionnaires were distributed in the survey, and 35 invalid blank samples and 51 men as the prominent pig breeders were eliminated. The study sample from Hebei, Henan, and Hubei, was 233, 236, and 245 households. Finally, 714 valid samples of rural women as pig breeders were obtained for the study purpose, accounting for $89.25 \%$ of the total sample. Additionally, to verify the questionnaire's representativeness, we performed the questionnaire's reliability and validity test. The results showed that Cronbach's $\alpha$ is 0.805, and Kaiser-Meyer-Olkin (KMO) value is 0.760 . The Bartlett sphere test $(p=0.000)$ is also significant, which means that the questionnaire has good reliability and validity.

\subsection{Variable Selection}

\subsubsection{Dependent Variable}

The dependent variable is rural women as pig breeders' environmental exposure. A few scholars have conducted theoretical and empirical exploration in assessing the level of environmental exposure, such as Rappaport and Smith (2010) have conducted "bottom-up" environmental monitoring and "top-down" bio-monitoring. However, bio-monitoring alone can be challenging to connect to specific exposures, making risk assessment and intervention, including regulatory decisions, more challenging (Wild, 2012). Since environmental exposure is the interaction between environmental risks and individual behavior, it generally depends on particular intervention (Oskar \& Stingone, 2020). Thus, we employed the exploratory factor analysis to evaluate the degree of environmental exposure from the perspective of behavioral economics, including women breeders' pre-exposure, in-exposure, and post-exposure intervention. Measurement items of the dependent variable are shown in Table 1.

The result of the rotated factor loading matrix of environmental exposure is presented in Table 2. From the table, it is clear that the KMO value is 0.765 , and the Bartlett sphere test (approximate chi-square value) is 4424.898 ( sig. $=0.000$ ), pointing that all variables are suitable for factor analysis. This paper employed the maximum variance method for factor 


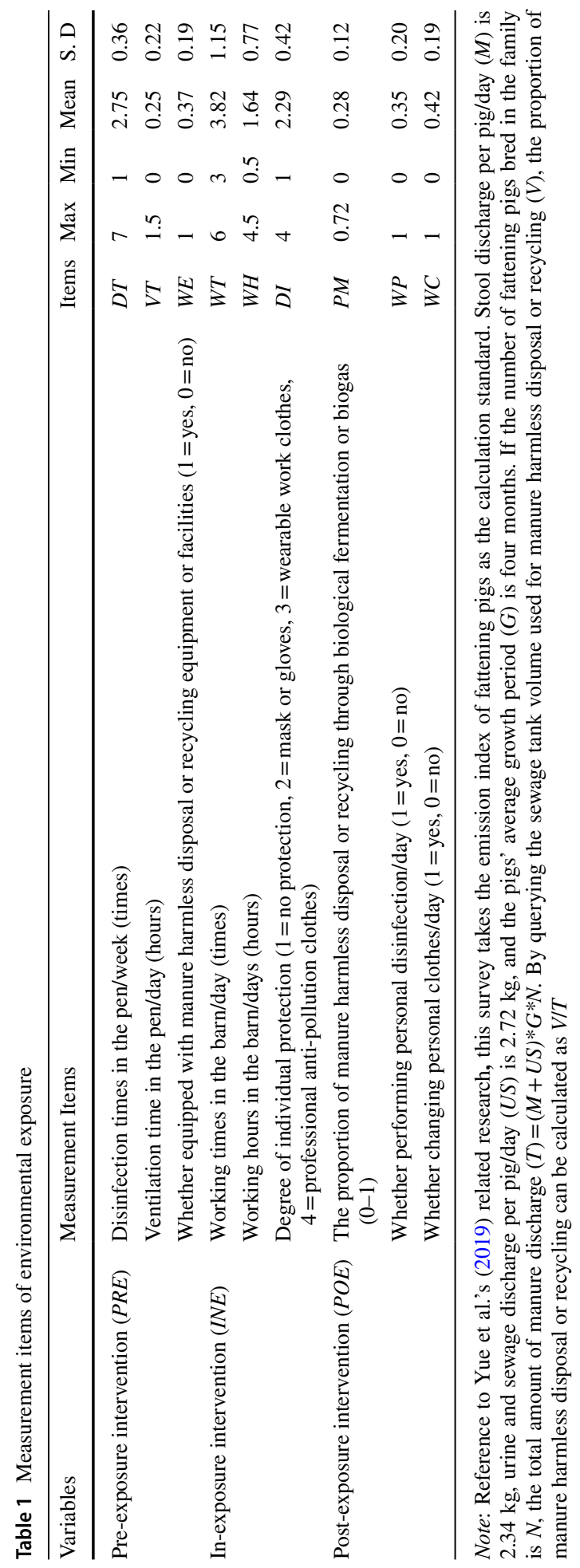


Table 2 Rotated factor loading matrix of environmental exposure

\begin{tabular}{lccc}
\hline Variables & \multicolumn{1}{l}{ PRE } & INE & POE \\
\hline DT & 0.862 & 0.352 & 0.003 \\
VT & 0.701 & 0.019 & 0.029 \\
WE & 0.754 & 0.054 & 0.102 \\
WT & 0.292 & 0.072 & 0.304 \\
WH & 0.302 & 0.086 & 0.254 \\
DI & 0.007 & 0.081 & 0.026 \\
PM & 0.002 & 0.029 & 0.065 \\
WP & 0.194 & 0.025 & 0.071 \\
WC & 0.018 & 0.201 & 0.076 \\
Variance contribution rate (\%) & 25.710 & 23.052 & 22.064 \\
Cumulative variance contribution rate (\%) & 70.826 & & \\
Bartlett sphere test (Approximate chi-square value) & 4424.898 & & \\
KMO value & 0.765 & & \\
Sig & 0.000 & & \\
\hline
\end{tabular}

Source Field Survey (2019)

rotation to make the results more reasonable and robust. The principal component method is applied to extract the three common factors having an eigenvalue greater than 1 . The cumulative variance contribution rate is $70.826 \%$. Finally, each common factor's variance contribution rate is regarded as the weight. The factor scores (Factor1-Factor3) of the three dimensions of environmental exposure are weighted and summed to calculate the degree of environmental exposure. The specific calculation formula is:

Degree of environmental exposure

$$
=25.710 \times \text { Factor } 1+23.052 \times \text { Factor } 1+22.064 \times \text { Factor } 1
$$

Given some negative factor analysis results, to make the result more intuitive, the sample's factor value is converted into an index of $1-100$ by following Bian and $\mathrm{Li}$ (2000). The conversion formula is as follow:

$$
\begin{aligned}
& \text { Factor }_{\text {afterconversion }}=\left(\text { Factor }_{\text {beforeconversion }}+B\right) A \\
& A=99 /\left(\text { Factor }_{\max }-\text { Factor }_{\text {Minimum }}\right) \\
& B=\left[\left(\left(\text { Factor }_{\max }-\text { Factor }_{\text {Minimum }}\right) / 99\right)\right]-\text { Factor }_{\text {Minimum }}
\end{aligned}
$$

Factor $_{\text {afterconversion }}$, Factor beforeconversion, $_{\text {Factor }}$ max , and Factor ${ }_{\text {Minimum }}$ represent the factor value of each sample after and before conversion, the maximum and minimum values of factors in all samples before conversion, respectively.

\subsubsection{Independent Variables}

The independent variables mainly include risk preference and health risk perception. Drawing on the views of Kachelmeier and Shehata (1992) and Charness et al. (2013), we applied experimental economics to measure the degree of women breeders' risk preferences. The research team designed 12 game plans in the questionnaire, and the respondents were asked to choose one by one from each plan. Once the respondent chose each plan, the 
investigator presented the next set of game plans. If the respondent chooses option B in each stage of game plans, then the respondent can't choose option A in subsequent games. Option A means winning a lottery ticket (the probability of winning is $50 \%$, and the winning amount is 600 yuan). Option B donates winning a fixed amount (showing an increasing trend from 50 to 599 yuan). Compared with choosing option A, choosing option B indicates that the respondents have a lower risk preference. Table 3 shows the experimental design of women breeders' risk preferences.

According to the data obtained from the experiment and the view of Qiu et al. (2015), the respondents' risk preference level is calculated by using the following formula:

$$
R P=1-\frac{\text { The number of choosing } B}{12}
$$

where $R P$ represents the respondents' risk preference degree, if the respondents choose option A for all 12 options, the risk preference value is 1, indicating that they are incredibly risk-taking. If all respondents choose option B for all options, their risk preference value is 0 , donating that the respondents are fully risk-aversion. Besides, women breeders' health risk perception is another crucial explanatory variable. The respondent is asked, "Do you think the environment pollution of the LPM harm your body or mind health?" The answer range is " $1=$ not possible at all, $2=$ not possible, $3=$ general, $4=$ possible, $5=$ very possible".

\subsubsection{Control Variables}

Some control variables such as women breeders' characteristics (age, education level, environmental pollution perception), family characteristics (number of migrant labors, area of farmland), business characteristics (breeding time, the proportion of breeding income), social network (channels of health information acquisition, number of communicating with other

Table 3 Experimental design of rural women as pig breeders' risk preferences

\begin{tabular}{lll}
\hline Coding of the game plan & $\begin{array}{l}\text { Option A: getting a lottery ticket (50\% probability of } \\
\text { getting 500 yuan) }\end{array}$ & $\begin{array}{l}\text { Option B: getting a } \\
\text { fixed amount(yuan) }\end{array}$ \\
\hline 01 & The probability of getting 600 yuan is $50 \%$ & 50 \\
02 & The probability of getting 600 yuan is $50 \%$ & 100 \\
03 & The probability of getting 600 yuan is $50 \%$ & 150 \\
04 & The probability of getting 600 yuan is $50 \%$ & 200 \\
05 & The probability of getting 600 yuan is $50 \%$ & 250 \\
06 & The probability of getting 600 yuan is $50 \%$ & 300 \\
07 & The probability of getting 600 yuan is $50 \%$ & 350 \\
08 & The probability of getting 600 yuan is $50 \%$ & 400 \\
09 & The probability of getting 600 yuan is $50 \%$ & 450 \\
10 & The probability of getting 600 yuan is $50 \%$ & 500 \\
11 & The probability of getting 600 yuan is $50 \%$ & 550 \\
12 & The probability of getting 600 yuan is $50 \%$ & 599 \\
\hline
\end{tabular}

Note 1yuan equals 0.1473 USD 


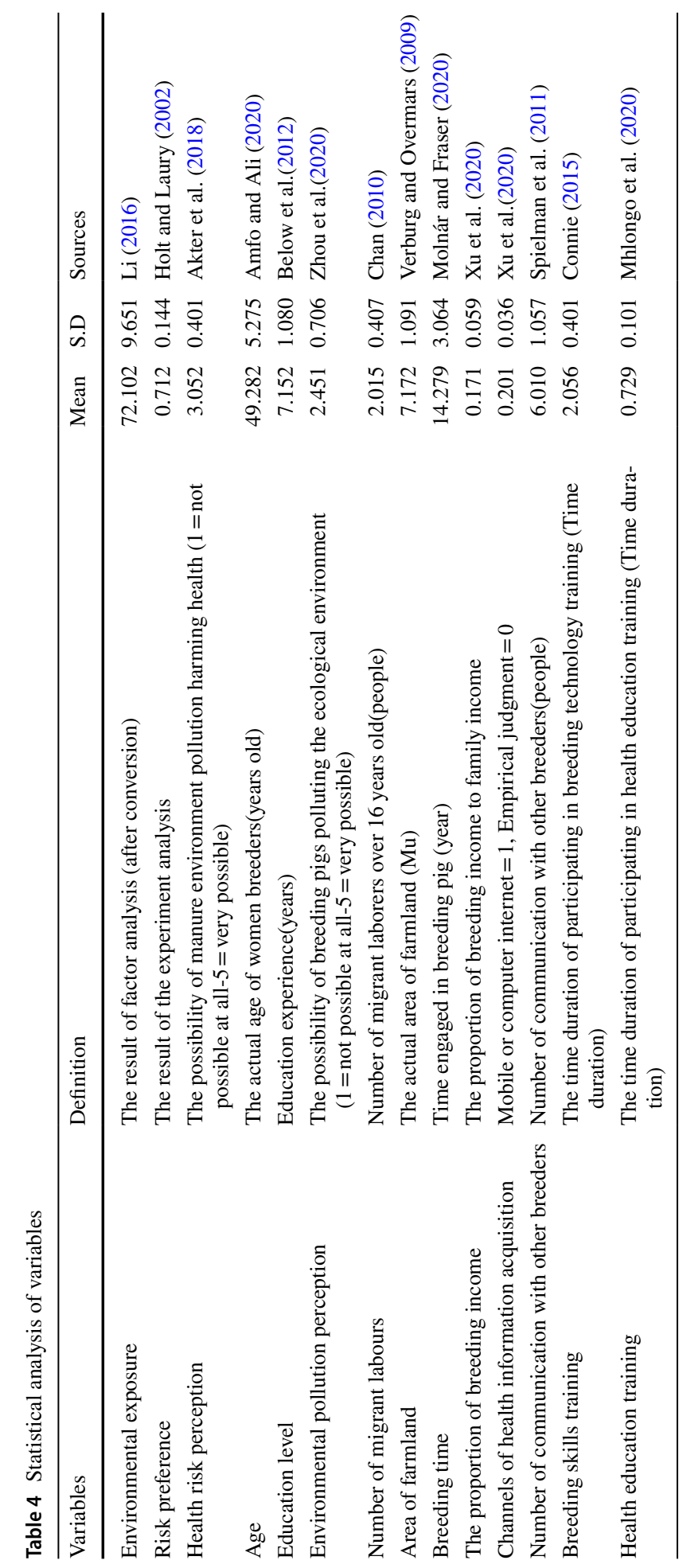


breeders), and government support (breeding skills training, health education training) are also incorporated in the model. The descriptive statistics of variables are shown in Table 4, and it is found that rural women breeders experience severe environmental exposure, and the degree of environmental exposure is $72.102(\operatorname{Min}=0, \max =100)$. They have a low level of health risk perception $($ Mean $=3.052)$ and a high level of risk preference $($ Mean $=0.712)$. Our interviews further confirmed that women farmers are willing to bear environmental pollution to increase income. The respondents' average age is 49.282 , and they mainly have received primary and secondary education. What needs attention is that rural women's environmental pollution awareness is relatively weak $($ Mean $=2.451)$, which indirectly reflects that women as pig breeders in the study area face higher health risks.

\subsection{Model Design}

The ordinary least square (OLS) is a standard and optimized method to minimize the error square and to give the best fit to the data (Lee et al., 2012). The role of OLS is that (1) the position data can be obtained by the OLS, and the sum of squared errors between position data and the actual data is the smallest; (2) the OLS can also be applied for curve fitting, such as adding interaction or square terms (Lin \& Benjamin, 2018). Thus, to empirically examine the effects of risk preference and health risk perception on rural women breeders' environmental exposure, the ordinary least square (OLS) model is constructed as follows:

$$
E P_{w p b}=\lambda+\beta_{1} R P+\beta_{2} H R P+\beta_{3} P E+\mu
$$

where $E P_{w p b}$ signifies the degree of environmental exposure, $R P$ donates women breeders' risk preference, $H R P$ indicates women breeders' health risk perception and $P E$ are the control variables, $\lambda 、 \beta_{1} 、 \beta_{2} 、 \beta_{3}$ are some coefficients to be estimated, $\mu$ is the error term.

Considering that there may occur simultaneity bias in the formula (4), that is, environmental exposure may also affect women breeders' health risk perception, for instance, breeders aware of possible respiratory disease risks may already take intervention measures, so their perception regarding health risk is already much more potent as compared to others. So to deal with this issue, an instrumental variable method is employed to cope with the endogeneity of health risk perception. By following the previous study of Frankel and Romer (1999), the nearest distance between breeder and hospital is taken as the instrumental variable. It is assumed that if the nearest distance is closer, then the breeders' health protection awareness and the level of health risk perception can be more robust and higher. In contrast, the nearest distance between breeders and hospitals can not directly influence the degree of women breeders' environmental exposure.

Finally, we employed the two-stage least squares (2SLS) regression approach to meet the study objective. The first stage is to make regression for the factors affecting women breeders' health risk perception. The specific form of the model is as follows: 


$$
H R P=\theta+\alpha_{1} R P+\alpha_{2} P E^{\prime}+\alpha_{3} I V+\varepsilon
$$

where $\theta$ donates the intercept term, $P E^{\prime}$ indicates the control variables, $I V$ signifies the instrumental variable, $\alpha_{1} 、 \alpha_{2} 、 \alpha_{3}$ are some coefficients to be estimated, $\varepsilon$ is an error term, the meanings of other variables are the same as formula (4).

\section{Results}

\subsection{Correlation Test}

A correlation test refers to analyzing two or more variables correlated (Erdfelder et al., 2009; Kong et al., 2020). The relationships between risk preference, health risk perception and women breeders' environmental exposure are also illustrated by the histograms and trend charts between risk preference and environmental exposure(mean), as well as health risk perception and environmental exposure(mean) respectively (Figs. 4, 5). It can be seen that there is a positive correlation between risk preference and women breeders' environmental exposure. Health risk perception has a negative correlation with women breeders'

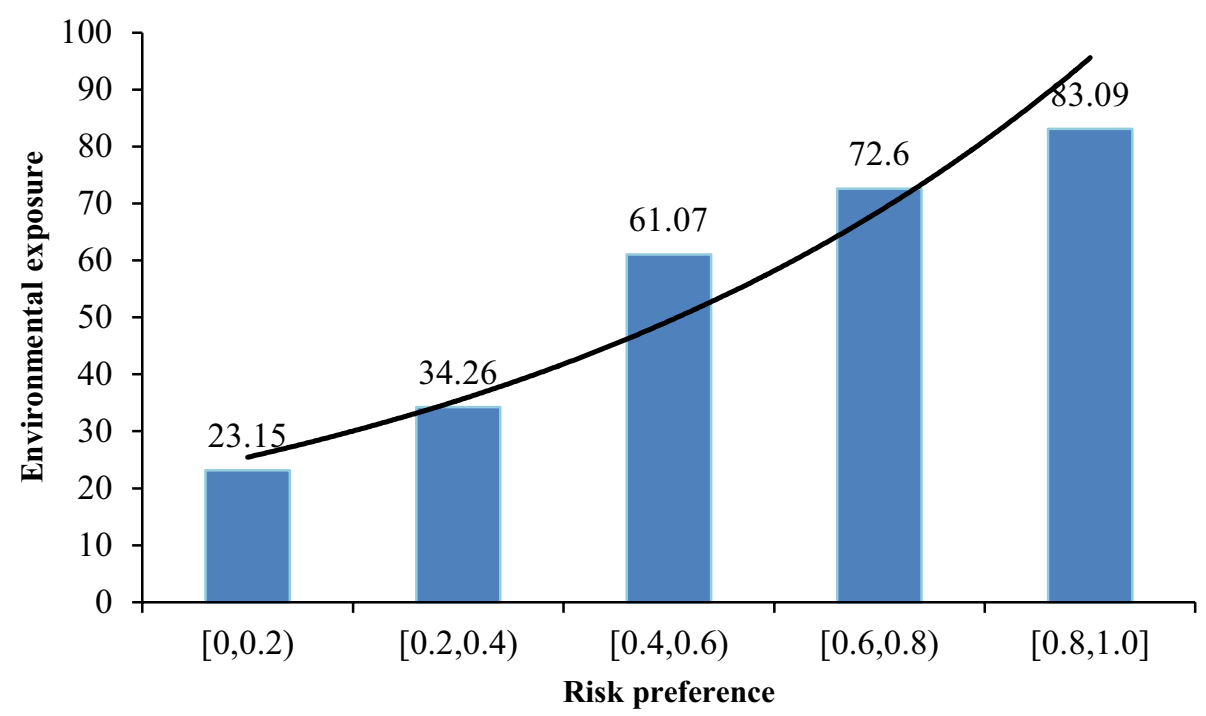

Fig. 4 Relationships between risk preference and environmental exposure 


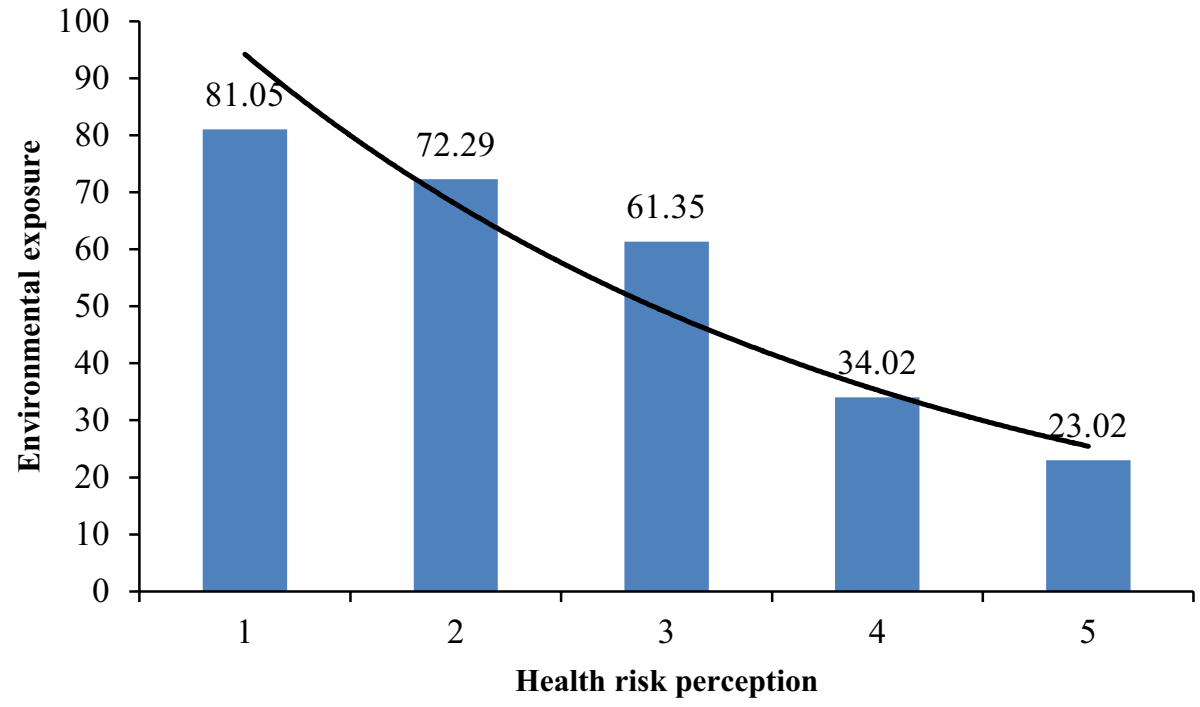

Fig. 5 Relationships between health risk perception and environmental exposure

environmental exposure. It infers that health risk perception weakens the effect of risk preference on women breeders' environmental exposure.

\subsection{Multi-Collinearity Test}

Multi-collinearity refers to the fact that the explanatory variables' precise or high correlation makes the linear regression model distorted or difficult to estimate (Jaafari et al., 2018). The variance inflation factor (VIF) is a reliable measure index of the variables' multi-collinearity, representing the ratio of the regression coefficient's variance to the

Table 5 Results of the multi-collinearity test

\begin{tabular}{lllr}
\hline Explained variable & Explanatory variables & \multicolumn{2}{l}{$\begin{array}{l}\text { Multi-collinearity } \\
\text { diagnosis }\end{array}$} \\
\cline { 2 - 3 } & & VIF & $1 /$ VIF \\
\hline Age & Education level & 1.076 & 0.929 \\
& Environmental pollution perception & 1.286 & 0.778 \\
Number of migrant labours & 2.012 & 0.497 \\
Area of farmland & 1.962 & 0.510 \\
Breeding time & 2.259 & 0.443 \\
The proportion of breeding income & 1.460 & 0.685 \\
Channels of health information acquisition & 2.001 & 0.500 \\
Number of communicating with other breeders & 1.205 & 0.830 \\
Breeding skills training & 1.208 & 0.828 \\
Health education training & 1.907 & 0.524 \\
& VIF mean & 1.638 & \\
\hline
\end{tabular}

Source Field Survey (2019) 
variance when the independent variables are assumed to be non-linearly correlated ( $\mathrm{Su}$ et al., 2020). In this research, we conducted the linear regression based on breeders' age regarded as explained variable and other variables attributed to explanatory variables. Finally, we obtained the variables' VIF values. Table 5 shows the multi-collinearity test results. It is apparent that the maximum value of VIF is 2.259 , the minimum value is 1.076 , and the average value is 1.638 , donating that the explanatory variables do not have severe multi-collinearity.

\subsection{Validity Test of Instrumental Variable}

The validity of instrumental variables is necessary to get consistent estimates (Maydeu-Olivares et al., 2019). Testing methods mainly include weak instrumentals test, which means instrumental variables are not related to endogenous variables and over-identification test, aiming to exclude unknown instrumental variables(Achten \& Lessmann, 2020). Firstly, as shown in Table 6, the closest distance between breeder and hospital exerts a positive and significant effect on women breeders' health risk perception. Still, it doesn't impact the degree of environmental exposure. Therefore, the instrumental variable is positively

Table 6 Results of 2SLS model estimation

\begin{tabular}{|c|c|c|c|c|}
\hline \multirow[t]{2}{*}{ Variables } & \multicolumn{2}{|c|}{$\begin{array}{l}\text { The first stage (Health risk } \\
\text { perception) }\end{array}$} & \multicolumn{2}{|c|}{$\begin{array}{l}\text { The second stage (Environ- } \\
\text { mental exposure) }\end{array}$} \\
\hline & coefficient & Standard error & coefficient & Standard error \\
\hline Risk preference & $0.0724 * * *$ & 0.0226 & $0.0825 * *$ & 0.0359 \\
\hline Health risk perception & & & $-0.1726^{* * *}$ & 0.0595 \\
\hline Age & 0.0429 & 0.0371 & 0.0219 & 0.0180 \\
\hline Education level & $0.0701^{*}$ & 0.0389 & $-0.0409 * *$ & 0.0184 \\
\hline Environmental pollution perception & 0.0017 & 0.0142 & $-0.0025 * *$ & 0.0011 \\
\hline Number of migrant labours & 0.0102 & 0.0072 & 0.0601 & 0.0408 \\
\hline Area of farmland & 0.0591 & 0.0405 & -0.0072 & 0.0109 \\
\hline Breeding time & $-0.0202 * * *$ & 0.0051 & $0.0708 * * *$ & 0.0176 \\
\hline Proportion of breeding income & 0.0005 & 0.0117 & 0.0621 & 0.0520 \\
\hline $\begin{array}{l}\text { Manure harmless or recycling equipment or } \\
\text { facilities }\end{array}$ & $-0.0704 *$ & 0.0380 & $-0.0409 *$ & 0.0228 \\
\hline Channels of health information acquisition & $0.0601 * * *$ & 0.0201 & -0.0108 & 0.0075 \\
\hline $\begin{array}{l}\text { Number of communicating with other breed- } \\
\text { ers }\end{array}$ & 0.0027 & 0.0126 & -0.0071 & 0.0203 \\
\hline Breeding skills training & $0.0065^{*}$ & 0.0036 & -0.0302 & 0.0131 \\
\hline Health education training & $0.0617 * * *$ & 0.0167 & $-0.0921 * *$ & 0.0413 \\
\hline $\begin{array}{l}\text { The closest distance between breeders and } \\
\text { hospital }\end{array}$ & $-0.0348 * *$ & 0.0160 & -0.0006 & 0.0125 \\
\hline Constant term & $0.2926 * * *$ & 0.0845 & $0.4062 * * *$ & 0.1456 \\
\hline $\mathrm{R}^{2}$ & 0.3031 & & & \\
\hline DWH test $\chi^{2}$ (P value) & $\begin{array}{l}8.0725 * * * \\
(0.0014)\end{array}$ & & & \\
\hline F value of the first stage & $12.0426 * * *$ & & & \\
\hline
\end{tabular}

Notes $* * * p<0.01, * * p<0.05, * p<0.1$ 
correlated with endogenous variables (health risk perception) but not closely related to the dependent variable. It is also concluded that the instrumental variables are identifiable. Secondly, the Durbin-Wu-Hausman (DWH) test value of 8.0725 is significant at $1 \%$, supporting the rejection of the null hypothesis and assuming that health risk perception is an exogenous variable. Equation (4) has serious endogeneity. Thirdly, the weak instruments is judged based on $\mathrm{F}$ value in first regression, if the $\mathrm{F}$ value is greater than 10, the null hypothesis, i.e. the instrumental variable is weak, and is rejected (Xu et al., 2018). Table 5 shows that the $\mathrm{F}$ value is $12.0426(P<0.01)$ and the instrumental variable chosen in the current study is relatively appropriate and reasonable.

\subsection{Results of 2SLS Model Estimation}

Table 6 shows the influencing factors of health risk perception (the first stage) and the effect of risk preference and health risk perception on women breeders' degree of environmental exposure (the second stage). It is found that (1) the risk preference positively and significantly affects women breeders' health risk perception; if the degree of risk preference increases by 1 unit, women breeders' level of health risk perception will increase by 7.24\%. (2) Risk preference positively influences breeders' environmental exposure. If the degree of risk preference increases by 1 unit, women breeders' degree of environmental exposure will increase by $8.25 \%$. Nevertheless, health risk perception has a significant and statistically negative effect on women breeders' environmental exposure. Suppose health risk perception increases by 1 unit, women breeders' degree of environmental exposure will decrease by $17.26 \%$. Moreover, the $\mathrm{R}^{2}$ is 0.3031 , indicating that the overall fitting result is good.

Moreover, based on the above analysis, it is concluded that risk preference, directly and indirectly, affects women breeders' degree of environmental exposure. Among them, the indirect effect depends on the breeders' level of health risk perception. To explore the role of the health risk perception, the impact of risk preference on women breeders' degree of environmental exposure is further analyzed by the direct and indirect impact of risk preference on the breeders' environmental exposure through constructing simultaneous equations. Accordingly, we combined Eqs. (4) and (5) to obtain the simplified equation as follows:

$$
E P_{w p b}=\lambda+\left(\beta_{1}+\beta_{2} \alpha_{1}\right) R P+\beta_{2} \alpha_{2} P E^{\prime}+\beta_{3} P E+\beta_{2} \alpha_{3} I V+\mu+\theta \beta_{2}+\varepsilon \beta_{2}
$$

where $\left(\beta_{1}+\beta_{2} \alpha_{1}\right)$ signifies that the comprehensive effects of risk preference on breeders' degree of environmental exposure $\beta_{2} \alpha_{1}$ indicate the indirect impact and $\beta_{1}$ denote direct impact. From Table 5, it is apparent that the direct effect of risk preference on women breeders' environmental exposure is 0.0825 , the indirect effect is -0.0125 $(-0.1726 \times 0.0724)$, and the indirect effect can offset $15.15 \%$ (ratio of indirect influence to direct influence) of the direct effect. Hence, health risk perception can reduce risk preference on women breeders' degree of environmental exposure.

Additionally, some control variables influencing women breeders' degree of environmental exposure show that education level, environmental pollution perception, and health education training can significantly reduce women breeders' degree of environmental exposure if the education level increases by one year, women breeders' degree of environmental exposure will decrease by $4.09 \%$. If environmental pollution perception increases by one unit, women breeders' degree of environmental exposure will reduce by $0.25 \%$. Moreover, if health training duration increases by one period, women breeders' degree of 
environmental exposure will decrease by $9.21 \%$. Besides, breeding time can also significantly increase women breeders' environmental exposure; if the breeding time increases one year, women breeders' degree of environmental exposure will increase by $7.08 \%$.

\subsection{Heterogeneity Analysis: Based on the Breeding Scale}

In theory, the larger the breeding scale, the more the manure waste and the higher the degree of environmental exposure (Kovačiková et al., 2020). In fact, in light of the specific research object, small and medium-scale women breeders in rural areas are focused rather than large-scale breeding companies or farms, with a higher manure disposal capability, less human capital investment, and a higher degree of standardized breeding (Wang et al., 2019). The economic structure and social relationships embedded in different breeding scales are heterogeneous (Si et al., 2020). Taking a breeding scale as a classification standard can deeply explain the heterogeneity of women breeders' environmental exposure in this research. Hence, we examined the effects of risk preference and health risk perception on different-scale women breeders' environmental exposure. In the sample, the maximum pig breeding scale is 49 heads, the minimum is two heads, and the average is 32.172 heads $(S . D .=4.064)$. Accordingly, we applied the group regression method and the 2SLS method to estimate the effects of the breeding scale's heterogeneity in Table 7.

The results showed that risk preference and health risk perception have no statistically significant influence on women breeders' environmental exposure with 2-10 heads. However, as the breeding scale gradually increases, the influence coefficient of risk preference gradually increases. The coefficient of health risk perception gradually decreases, indicating that the effect of risk preference and health risk perception on environmental

Table 7 Results of 2SLS model estimation based on the heterogeneity of breeding scale

\begin{tabular}{|c|c|c|c|c|}
\hline \multirow[t]{2}{*}{ Variables } & \multicolumn{2}{|c|}{ The first stage (Health risk perception) } & \multicolumn{2}{|c|}{$\begin{array}{l}\text { The second stage (Environmental } \\
\text { exposure) }\end{array}$} \\
\hline & Coefficient & Standard error & Coefficient & Standard error \\
\hline \multicolumn{5}{|c|}{ Scale: $2-10$ heads (131 breeders) } \\
\hline Risk preference & 0.0214 & 0.0171 & 0.0125 & 0.0089 \\
\hline Health risk perception & & & -0.0126 & 0.0132 \\
\hline \multicolumn{5}{|c|}{ Scale: $11-20$ heads (141 breeders) } \\
\hline Risk preference & $0.0410 *$ & 0.0227 & $0.0175 * *$ & 0.0079 \\
\hline Health risk perception & & & $-0.0106^{*}$ & 0.0057 \\
\hline \multicolumn{5}{|c|}{ Scale: $21-30$ heads (145 breeders) } \\
\hline Risk preference & $0.0515^{*}$ & 0.0271 & $0.0375 * * *$ & 0.0125 \\
\hline Health risk perception & & & $-0.0306^{*}$ & 0.0161 \\
\hline \multicolumn{5}{|c|}{ Scale: $31-40$ heads (152 breeders) } \\
\hline Risk preference & $0.0670 * *$ & 0.0304 & $0.0512 * *$ & 0.0244 \\
\hline Health risk perception & & & $-0.0426^{* *}$ & 0.0177 \\
\hline \multicolumn{5}{|c|}{ Scale: $41-49$ heads (143 breeders) } \\
\hline Risk preference & $0.0419 *$ & 0.0229 & $0.0266^{*}$ & 0.0140 \\
\hline Health risk perception & & & $-0.0206^{*}$ & 0.0114 \\
\hline
\end{tabular}

$* * * p<0.01, * * p<0.05, * p<0.1$ 
exposure of women breeders with 11-40 heads is steadily increased. Surprisingly, the effects of risk preference and health risk perception on breeders' environmental exposure of women breeders' environmental exposure with 41-49 heads are unexpectedly weaker. Further, this trend of effects of risk preference and health risk perception is consistent with the offsetting effect of health risk perception with $2.15 \%$ (2-10 heads) $<2.48 \%(11-20$ heads $)<3.24 \%$ (41-49 heads) $<4.20 \%$ (21-30 heads) $<5.57 \%(31-40$ heads $)>3.24 \%$ (41-49 heads). Hence, it is concluded that the effect of risk preference and health risk perception on women breeders' environmental exposure is an inverted U-shaped relationship.

\subsection{Robustness Checks}

In this research, we employed a method of replacing instrumental variables for the robustness check. The relationship network's range and strength can significantly improve the individual's risk perception level (Fan et al., 2019; Meza et al., 2020). Suppose women breeders have more relatives and friends engaged in health-related work, such as doctors, health insurance sales personnel, health department personnel, etc., in that case, there will be a higher level of health risk perception. Thus, we modified the instrumental variable to "number of relatives and friends engaged in health-related work" and examined the effects of risk preference and health risk perception on women breeders' degree of environmental exposure. From Table 8, it is clear that risk preference exerts positive and significant effects on women breeders' health risk perception and environmental exposure. However, health risk perception significantly inhibits the women breeders' degree of environmental exposure. Accordingly, improving the level of health risk perception weakens the effects of risk preference on women breeders' environmental exposure significantly. The number of relatives and friends engaged in health-related work has a positive and statistically significant impact on health risk perception. Still, it does not affect women breeders' degree of environmental exposure. Therefore, there is no significant difference between the robustness test results in Table 8 and the benchmark regression results in Table 6, indicating that the 2 SLS model estimation results are relatively robust.

Table 8 Results of the robustness test

\begin{tabular}{|c|c|c|c|c|}
\hline \multirow[t]{2}{*}{ Variables } & \multicolumn{2}{|c|}{$\begin{array}{l}\text { The first stage (Health risk percep- } \\
\text { tion) }\end{array}$} & \multicolumn{2}{|c|}{$\begin{array}{l}\text { The second stage (Environmen- } \\
\text { tal exposure) }\end{array}$} \\
\hline & Coefficient & Standard error & Coefficient & Standard error \\
\hline Risk preference & $0.0723 * * *$ & 0.0210 & $0.0819 * *$ & 0.0375 \\
\hline Health risk perception & & & $-0.1725^{* * *}$ & 0.0536 \\
\hline $\begin{array}{l}\text { Number of relatives and friends } \\
\text { engaged in health-related work }\end{array}$ & $0.0427 * *$ & 0.0186 & 0.0179 & 0.0128 \\
\hline Control variables & Controlled & Controlled & Controlled & Controlled \\
\hline
\end{tabular}

$* * * p<0.01, * * p<0.05, * p<0.1$ 


\section{Discussion}

\subsection{Theoretical Innovation}

Women's health issues, prioritized by the UN Global Strategy, such as food security (Aziz et al., 2020), health check-ups (Scheel et al., 2019), vaccine distribution (Senapati et al., 2017), pregnancy \& nutrition (Nath et al., 2019), cognitive health (Akter et al., 2020), and domestic violence (Koenig et al., 2003) have always been the key concerns especially in deprived rural areas of developing countries. However, with the aggravation of rural environment pollution, many women are fully exposed to environmental pollution, but existing literature paid little or no attention to this issue. Accordingly, we reinterpreted the concept of "environmental exposure." We believed that environmental exposure is the interaction between environmental risk factors and individuals' behavioural intervention, determining the heterogeneity degree of environmental exposure. Besides, we innovatively evaluated the degree of environmental exposure from pre-exposure, in-exposure, and post-exposure behavioural interventions, which made some theoretical contributions and provided a new insight to explore influencing factors to reduce the degree of environmental exposure. Most importantly, consistent with other scholars' studies concerning "environmental exposure" (Kippler et al., 2012; Larsson et al., 2014), we have focused on Chinese rural women farmers exposed to severe environmental pollution emitted from manure. Further, we incorporated risk preference and health risk perception into women breeders' environmental exposure framework from the perspective of behavioral economics. We examined the effects of risk preference and health risk perception on women breeders' environmental exposure. Therefore, our research is a new addition in enriching the research scope of environmental and agricultural economics.

\subsection{Discussion of Empirical Results}

Our research confirmed that an increase in the level of risk preference could enhance women breeders' health risk perception; that is, risk-taking breeders, in general, have a higher level of health risk perception. However, the findings are inconsistent with some scholars, who argued that under the same risk level, risk-aversion farmers are inclined to overestimate the severity of risks due to weak risk resistance (Dohmen et al., 2011), insufficient risk diversification tools (Tong et al., 2019), and difficulty in making up for risk losses (Meraner \& Finger, 2019), resulting in a higher level of risk perception; risk-taking farmers are prone to have a lower level of risk perception owning to a complete risk transfer mechanism (Zhao et al., 2017), better alternative livelihood strategies (Kemeze et al., 2020), and timely compensation for risk losses (Holt \& Laury, 2002). Possible explanations for the differences in research conclusions are that: existing studies generally ignored the heterogeneity of risk perceptions based on socio-economic attributes(Flaten et al., 2005). Specifically, environmental, public health, and natural disasters risk perceptions have obvious externalities and altruistic properties, sometimes included in quasi-public goods. Risk-taking farmers exhibit a low level of risk perception (Dohmen et al., 2011). However, other risks such as health, food, and unemployment risk perception are closely related to individuals' interests(Wang et al., 2020). Even if farmers have a high degree of risk preference, they can enhance the risk perceptions through multi-channel information acquisition and broadening acquaintance networks (Meza et al., 2020). Hence, although women 
breeders probably allow manure pollution and don't dispose of it harmlessly, they still can enhance the level of health risk perception through communication with other breeders, news media, or government agendas. The high cost of manure cycling, the weak incentive of government support, and the concealment of risk realization make health risk perception vulnerable and drive individuals' towards environmental pollution ( $\mathrm{Si}$ et al., 2020).

Our research showed that a higher degree of risk preference has become a key determinant of rural women breeders' exposure to severe LPM pollution. This result confirmed the findings of Flaten et al. (2005), Menapace et al. (2016), Meraner and Finger (2019) and Hellerstein et al. (2013), who found that risk-taking farmers are less likely to apply risk management strategies related to labor, land, and capital input. Risk-taking women breeders are usually unwilling to spend additional family income purchasing or buying disinfectant, protective clothing, and manure harmless disposal or recycling facilities. Besides, the degree of rural mechanical breeding is much lower, and women breeders tend to maintain stable production and operation by increasing working hours and frequency. Hence, it can be seen that the higher the degree of risk preference, the fewer measures are taken by women breeders to combat manure pollution and so vulnerable to a higher degree of environmental exposure.

Meanwhile, Wang et al. (2020) and Herberich and List (2012) believed that this intuitive result stems from the fact that risk-taking individuals psychologically allow risks, not linked to individuals' interests, to be infinitely amplified and lose effective management. Breeding pig is relatively intensive, and the negative externality of manure pollution is highly substantial. If any household does not reduce environmental exposure, other breeders will often leave it alone and pay no close attention.

Our results showed that the health risk perception weakens and offsets $15.15 \%$ of risk preference's damaging effects. Consequently, risk preference may continue to make women farmers' exposure to a high level. In other words, only when the inhibitory effect of health risk perception is higher than the promotion effect of risk preference, the environmental exposure of women breeders may be at a lower degree. Consistent with the findings of Bryan and Kandulu (2011) and Si et al. (2020), who considered that risk perception could enable farmers to strengthen risk management and implement risk intervention by evaluating the degree of risk damage, calculating the ratio of cost-benefit, and measuring the margin and expected utility. Suppose women breeders' health risk perception is higher. And in that case, they will try their best to reduce the direct damage of fecal odor to the respiratory system by taking appropriate protective measures, reducing the frequency and time of manure contact, and increasing the ventilation frequency disinfection. However, inconsistent with the studies of Kahneman and Tversky (1984) and Qiu et al., (2020a, 2020b), who believed that risk perception plays a positive moderating effect of risk preference on farmers' risk decisions.

Moreover, Zhao et al. (2017), in their study, confirmed that product safety risk perception significantly enhances the risk attitudes of apple farmers' towards safety production decisions. Hence, our research also confirmed the conclusion that the heterogeneity of risk perception dimensions significantly showed differences due to socio-economic attributes. Besides, inconsistent with existing studies such as Kemeze et al. (2020), and Sarwosri and Mußhoff (2020), and He et al. (2020), our results further confirmed that the effect of risk preference and health risk perception on women breeders' environmental exposure is an inverted U-shaped relationship. 


\section{Research Limitations}

Although we have made some novel contributions to rural women breeders' environmental exposure from theoretical and empirical analysis, some flaws still exist, that may provide new research avenues for other scholars and researchers. Firstly, we took only rural women breeders of small and medium-scale as the sample. Future research can also select moderately and large-scale breeders, having a higher ability to prevent and control manure pollution and make a comparative analysis of whether all women breeders expose to environmental pollution respond in the same manner (Kovačiková et al., 2020; Wang et al., 2019). Secondly, we mainly discussed the relationship of risk preference, health risk perception, and women breeders' environmental exposure. According to the "Attitude-Context-Behavior" theory (Guagnano et al., 1995), the moderating effect of external contextual factors such as organizational support can also be used to explore the effect of risk perception on breeders' environmental exposure. Limited to the difficulty in obtaining survey data, we did not discuss the role of organizational support. Thirdly, although we have dealt with the endogeneity between health risk perception and women breeders' environmental exposure, we have not considered the endogeneity of missing variables and measurement errors. Finally, limited to research purposes and data acquisition, the mediating effect of environmental exposure in the impacts of risk preference and health risk perception on environmental exposure, the direct effect of risk preference and health risk perception on the health status, and the direct effect of environmental exposure on the health status of rural breeders are not examined. Consequently, these shortcomings can pave new avenues for researchers and academicians to amend these flaws in their future research work.

\section{Conclusion and Policy Implications}

In the existing literature, little attention has been given to women groups and their unheard voices in the pollution control of the LPM, making them more vulnerable to frequent and severe environmental exposure. Unlike previous studies, this study opted survey as well as experimental data of 714 Chinese rural women as pig breeders to examine the effects of risk preference and health risk perception on their exposure to the environment. The degree of environmental exposure is evaluated in terms of women breeders' pre-exposure, in-exposure, post-exposure interventions. The results showed that rural women breeders face severe environmental exposure, and the degree of environmental exposure is up to 72.102 (Min=0, $\max =100$ ). Moreover, risk preference positively and significantly influences women breeders' health risk perception and environmental exposure. If the degree of risk preference increases by 1 unit, women breeders' level of health risk perception will increase by $7.24 \%$, and the degree of environmental exposure will increase by $8.25 \%$, respectively.

Nevertheless, health risk perception has a significant and statistically negative effect on women breeders' environmental exposure. If the level of health risk perception increases by 1 unit, the degree of environmental exposure will decrease by $17.26 \%$. Therefore, it is believed that health risk perception can offset the effects of risk preference on women breeders' environmental exposure by $15.15 \%$. Furthermore, by considering the heterogeneity of breeding scale, the effect of risk preference and health risk perception on women breeders' environmental exposure with 11-40 heads is more substantial. In comparison, the effects of breeding scale with 2-10 heads and 41-49 head are relatively weak. Hence, 
the effect of risk preference and health risk perception on women breeders' environmental exposure presented an inverted U-shaped relationship.

In the last, this study provided some essential guidelines for policymakers to reduce the women breeders' degree of environmental exposure. Firstly, the government should provide information regarding LPM environmental pollution to women breeders through radio, television, or Internet media. They must be aware that the stench, sewage, bacteria, and viruses produced by LPM may worsen their health and encourage them to take the initial steps in implementing the LPM harmless disposal or recycling strategies. Secondly, the government should subsidize women breeders to build or purchase harmless disposal or recycling equipment and facilities such as anti-pollution protective clothing, disinfectant liquids, and other production materials. Thirdly, the health department should enhance women's knowledge towards health concerns and provide them with at least two regular free physical examinations per year. Moreover, the livestock management department should provide financial support to women breeders, to adopt green and standardized breeding technologies and let aware of their susceptibility to physical or mental health by constant exposure to LPM. Finally, the findings of the current China's sample can provide useful experience to other developing countries in reducing the environmental exposure of rural women.

Acknowledgements This work was supported by National Natural Science Foundation of China (Grant No. 72103161), Humanities and Social Science Fund of the Ministry of Education of the People's Republic of China (Grant No. 20YJA790089), Research Project of Major Theoretical and Practical Issues Program in Social Sciences of Shaanxi Province, China (Grant No. 20ST-94, 2021ND0202), Social Science Foundation of Shaanxi Province, China (Grant No. 2021D008), Special scientific research project of Education Department of Shaanxi Provincial Government (Grant No. 21JK0203).

Authors' Contributions Ruishi Si: writing-original draft preparation and editing; Xueqian Zhang: conceptualization and methodology; Yumeng Yao: data curation; Qian Lu: supervision, visualization, and validation.

Availability of Data and Material Extra data is available by emailing to siruishi@126.com on reasonable request.

\section{Declarations}

Conflict of interest The authors declare that they have no conflict of interest.

\section{References}

Achten, S., \& Lessmann, C. (2020). Spatial inequality, geography and economic activity. World Development, 136, 105114. https://doi.org/10.1016/j.worlddev.2020.105114

Adegbeye, M. J., Elghandour, M. M. M. Y., Monroy, J. C., Abegunde, T. O., Salem, A. Z. M., BarbabosaPliego, A., \& Faniyi, T. O. (2019). Potential influence of Yucca extract as feed additive on greenhouse gases emission for a cleaner livestock and aquaculture farming-A review. Journal of Cleaner Production, 239(3), 118074. https://doi.org/10.1016/j.jclepro.2019.118074

Akter, F., Rahman, M., Pitchik, H. O., Winch, P. J., Fernald, L. C. H., Huda, T. M. N., et al. (2020). Adaptation and integration of psychosocial stimulation, maternal mental health and nutritional interventions for pregnant and lactating women in rural Bangladesh. International Journal of Environmental Research and Public Health, 17(17), 1-16. https://doi.org/10.3390/ijerph17176233

Akter, M., Fan, L., Rahman, M. M., Geissen, V., \& Ritsema, C. J. (2018). Vegetable farmers'behaviour and knowledge related to pesticide use and related health problems: A case study from Bangladesh. Journal of Cleaner Production, 200, 122-133. https://doi.org/10.1016/j.jclepro.2018.07.130 
Ali, B., Ullah, A., \& Khan, D. (2020). Does the prevailing Indian agricultural ecosystem cause carbon dioxide emission A consent towards risk reduction? Environmental Science and Pollution Research. https://doi.org/10.1007/s11356-020-10848-3

Amfo, B., \& Ali, E. B. (2020). Climate change coping and adaptation strategies: How do cocoa farmers in Ghana diversify farm income? Forest Policy and Economics, 119(7), 102265. https://doi.org/10. 1016/j.forpol.2020.102265

Andersen, Z. J., Raaschou-Nielsen, O., Ketzel, M., Jensen, S. S., Hvidberg, M., Loft, S., et al. (2012). Diabetes incidence and long-term exposure to air pollution: A cohort study. Diabetes Care, 35(1), 92-98. https://doi.org/10.2337/dc11-1155

Aziz, N., Nisar, Q. A., Koondhar, M. A., Meo, M. S., \& Rong, K. (2020). Analyzing the women's empowerment and food security nexus in rural areas of Azad Jammu \& Kashmir, Pakistan: By giving consideration to sense of land entitlement and infrastructural facilities. Land Use Policy, 94(11), 104529. https://doi.org/10.1016/j.landusepol.2020.104529

Beek, V. (2010). Even healthy pigs can give producers a headache. Pig Progress, 26(3), 6-8.

Below, T. B., Mutabazi, K. D., Kirschke, D., Franke, C., Sieber, S., Siebert, R., \& Tscherning, K. (2012). Can farmers'adaptation to climate change be explained by socio-economic household-level variables? Global Environmental Change, 22(1), 223-235. https://doi.org/10.1016/j.gloenvcha.2011.11.012

Bian, Y., \& Li, Y. (2000). Social network capital of Chinese urban families. Tsinghua Sociology Review, 2, $1-18$.

Bo, H., \& Sterken, E. (2007). Attitude towards risk, uncertainty, and fixed investment. North American Journal of Economics and Finance, 18(1), 59-75. https://doi.org/10.1016/j.najef.2006.09.001

Boers, S., Hagoort, K., Scheepers, F., \& Helbich, M. (2018). Does residential green and blue space promote recovery in psychotic disorders? A cross-sectional study in the Province of Utrecht, the Netherlands. International Journal of Environmental Research and Public Health, 15(10), 1-8. https://doi.org/10. 3390/ijerph15102195

Bontems, P., \& Thomas, A. (2006). Regulating nitrogen pollution with risk averse farmers under hidden information and moral hazard. American Journal of Agricultural Economics, 88(1), 57-72.

Botzen, W., Aerts, J., \& van den Bergh, J. (2009). Willingness of homeowners to mitigate climate risk through insurance. Ecological Economics, 68(8-9), 2265-2277.

Bryan, B., \& Kandulu, J. (2011). Designing a policy mix and sequence for mitigating agricultural nonpoint source pollution in a water supply catchment. Water Resources Management, 25, 875-892.

Buck Louis, G. M., Yeung, E., Sundaram, R., Laughon, S. K., \& Zhang, C. (2013). The exposomeExciting opportunities for discoveries in reproductive and perinatal epidemiology. Paediatric and Perinatal Epidemiology, 27(3), 229-236. https://doi.org/10.1111/ppe.12040

Bussink-Voorend, D., Bussink, A. P., Falama, A. M., \& Stekelenburg, J. (2020). Health indicators of pregnant women in tonkolili district, rural sierra leone. International Journal of Environmental Research and Public Health, 17(11), 1-9. https://doi.org/10.3390/ijerph17113918

Cai, Y., Zhou, M., \& Julian, C. (2018). Research on the impact of air pollution on labor supply: Based on the perspective of healthy human capital. Social Security Research, 6, 59-68.

Cao, Y., Bai, Y., \& Zhang, L. (2020). The impact of farmland property rights security on the farmland investment in rural China. Land Use Policy, 97(9), 104736. https://doi.org/10.1016/j.landusepol. 2020.104736

Chan, K. W. (2010). The household registration system and migrant labor in China: Notes on a debate. Population and Development Review, 36(2), 357-364. https://doi.org/10.1111/j.1728-4457.2010. 00333.x

Charness, G., Gneezy, U., \& Imas, A. (2013). Experimental methods: Eliciting risk preferences. Journal of Economic Behavior and Organization, 87, 43-51. https://doi.org/10.1016/j.jebo.2012.12.023

Connie, Z. (2015). Keeping talents for advancing service firms in Asia. Journal of Service Management, 20(5), 482-502.

Dai, Y., Huo, X., Cheng, Z., Faas, M. M., \& Xu, X. (2020). Early-life exposure to widespread environmental toxicants and maternal-fetal health risk: A focus on metabolomic biomarkers. Science of the Total Environment, 739, 139626. https://doi.org/10.1016/j.scitotenv.2020.139626

Dohmen, T., Falk, A., Huffman, D., Sunde, U., Schupp, J., \& Wagner, G. G. (2011). Individual risk attitudes: Measurement, determinants, and behavioral consequences. Journal of the European Economic Association, 9(3), 522-550. https://doi.org/10.1111/j.1542-4774.2011.01015.x

Dong, S., Sui, B., Shen, Y., Meng, H., Zhao, L., Ding, J., et al. (2020). Investigation and analysis of the linkage mechanism and whole process cost of livestock manure organic fertilizer. International Journal of Agricultural and Biological Engineering, 13(2), 223-227. https://doi.org/10.25165/j. ijabe.20201302.5682 
Duan, W., Shen, J., Hogarth, N. J., \& Chen, Q. (2021). Risk preferences significantly affect household investment in timber forestry: Empirical evidence from Fujian China. Forest Policy and Economics, 125(2), 102421. https://doi.org/10.1016/j.forpol.2021.102421

Dzhambov, A. M., Markevych, I., Hartig, T., Tilov, B., Arabadzhiev, Z., Stoyanov, D., et al. (2018). Multiple pathways link urban green and bluespace to mental health in young adults. Environmental Research, 166(5), 223-233. https://doi.org/10.1016/j.envres.2018.06.004

Elwell, R. (2009). Understanding and managing risk attitude. Ergonomics, 52(2), 271-272.

Erdfelder, E., FAul, F., Buchner, A., \& Lang, A. G. (2009). Statistical power analyses using G*Power 3.1: Tests for correlation and regression analyses. Behavior Research Methods, 41(4), 1149-1160.

Fan, G., Lin, Y., Wang, L., Jia, C., Chen, X., \& Zhu, Q. (2019). Investigation and research on Internet use behavior and health awareness of the elderly. General Nursing, 17(11), 1390-1392.

Flaten, O., Lien, G., Koesling, M., Valle, P. S., \& Ebbesvik, M. (2005). Comparing risk perceptions and risk management in organic and conventional dairy farming: Empirical results from Norway. Livestock Production Science, 95(1-2), 11-25. https://doi.org/10.1016/j.livprodsci.2004.10.014

Frankel, J., \& Romer, D. (1999). Does trade cause growth? American Economic Review, 89(3), 379-399.

Ginja, S., Jackson, K., Newham, J. J., Henderson, E. J., Smart, D., \& Lingam, R. (2020). Rural-urban differences in the mental health of perinatal women: A UK-based cross-sectional study. $B M C$ Pregnancy and Childbirth, 20(1), 1-11. https://doi.org/10.1186/s12884-020-03132-2

Guagnano, G. A., Stern, P. C., \& Dietz, T. (1995). Influences on attitude-behavior relationships: A natural experiment with curbside recycling. Environment and Behavior, 27(5), 699-718. https://doi. org/10.1177/0013916595275005

Haase, M., Rösch, C., \& Ulrici, O. (2017). Feasibility study on the processing of surplus livestock manure into an organic fertilizer by thermal concentration-The case study of Les Plenesses in Wallonia. Journal of Cleaner Production, 161, 896-907. https://doi.org/10.1016/j.jclepro.2017. 05.207

He, R., Jin, J., Kuang, F., Zhang, C., \& Guan, T. (2020). Farmers'risk cognition, risk preferences and climate change adaptive behavior: A structural equation modeling approach. International Journal of Environmental Research and Public Health, 17(1), 1-13. https://doi.org/10.3390/ijerph17010085

Hellerstein, D., Higgins, N., \& Horowitz, J. (2013). The predictive power of risk preference measures for farming decisions. European Review of Agricultural Economics, 40(5), 807-833. https://doi.org/ 10.1093/erae/jbs043

Herberich, D. H., \& List, J. A. (2012). Digging into background risk: Experiments with farmers and students. American Journal of Agricultural Economics, 94(2), 457-463. https://doi.org/10.1093/ ajae/aar070

Herrero, M., Wirsenius, S., Henderson, B., Rigolot, C., Thornton, P., Havlík, P., et al. (2015). Livestock and the environment: What have we learned in the past decade? Annual Review of Environment and Resources, 40, 177-202. https://doi.org/10.1146/annurev-environ-031113-093503

Hoffmann, B., Beer, M., Reid, S., Mertens, P., Oura, C., van Rijn, P., \& King, D. (2009). A review of RT-PCR technologies used in veterinary virology and disease control: Sensitive and specific diagnosis of five livestock diseases notifiable to the World Organisation for Animal Health. Veterinary Microbiology, 139(1-2), 1-23.

Holt, C., \& Laury, S. (2002). Risk aversion and incentive effects. American Economic Review, 92(5), 1644-1655.

Imran, M., \& Ozcatalbas, O. (2020). Determinants of household cooking fuels and their impact on women's health in rural Pakistan. Environmental Science and Pollution Research, 27(19), 2384923861. https://doi.org/10.1007/s11356-020-08701-8

Jaafari, A., Zenner, E. K., \& Pham, B. T. (2018). Wildfire spatial pattern analysis in the Zagros Mountains, Iran: A comparative study of decision tree based classifiers. Ecological Informatics, 43, 200-211. https://doi.org/10.1016/j.ecoinf.2017.12.006

Jeswani, H. K., Whiting, A., Martin, A., \& Azapagic, A. (2019). Environmental and economic sustainability of poultry litter gasification for electricity and heat generation. Waste Management, 95, 182-191. https://doi.org/10.1016/j.wasman.2019.05.053

Jurado, C., Martínez-Avilés, M., La Torre, A. D., Štukelj, M., de Ferreira, H. C., Cerioli, M., et al. (2018). Relevant measures to prevent the spread of African Swine Fever in the European Union Domestic Pig Sector. Frontiers in Veterinary Science, 5(4), 1-16. https://doi.org/10.3389/fvets. 2018.00077

Kachelmeier, S., \& Shehata, M. (1992). Examining risk preferences under high monetary incentives: Experimental evidence from the people's republic of China. American Economic Review, 82(5), 1120-1141. 
Kahneman, D., \& Tversky, A. (1979). Prospect theory: An analysis of decision under risk. Econometrica, 47(2), 263-292.

Kahneman, D., \& Tversky, A. (1984). Choice, values and frames. American Psychologist, 39(4), 341-350.

Kemeze, F. H., Miranda, M. J., Kuwornu, J. K. M., \& Anim-Somuah, H. (2020). Smallholder farmer risk preferences in northern Ghana: Evidence from a controlled field experiment. Journal of Development Studies, 56(10), 1894-1908. https://doi.org/10.1080/00220388.2020.1715945

Kippler, M., Tofail, F., Hamadani, J. D., Gardner, R. M., Grantham-McGregor, S. M., Bottai, M., \& Vahter, M. (2012). Early-life cadmium exposure and child development in 5-year-old girls and boys: A cohort study in rural Bangladesh. Environmental Health Perspectives, 120(10), 14621468. https://doi.org/10.1289/ehp.1104431

Koenig, M. A., Ahmed, S., Hossain, M. B., \& Alam Mozumder, A. B. M. K. (2003). Women's status and domestic violence in rural Bangladesh: Individual- and community-level effects. Demography, 40(2), 269-288. https://doi.org/10.2307/3180801

Kong, X., Cao, Y., Luo, X., \& He, L. (2020). The correlation analysis between the appearance anxiety and personality traits of the medical staff on nasal and facial pressure ulcers during the novel coronavirus disease 2019 outbreak. Nursing Open, 3, 1-9. https://doi.org/10.1002/nop2.613

Kovačiková, L., Kaupová, S. D., Poláček, L., Velemínský, P., Limburský, P., \& Brůžek, J. (2020). Pigbreeding management in the early medieval stronghold at Mikulčice(Eighth-Ninth Centuries, Czech Republic). Environmental Archaeology, 1(4), 1-15. https://doi.org/10.1080/14614103.2020.1782583

Kuhn, L., Balezentis, T., Hou, L., \& Wang, D. (2020). Technical and environmental efficiency of livestock farms in China: A slacks-based DEA approach. China Economic Review, 62, 1-18. https://doi.org/10. 1016/j.chieco.2018.08.009

Larsson, K., Ljung Björklund, K., Palm, B., Wennberg, M., Kaj, L., Lindh, C. H., et al. (2014). Exposure determinants of phthalates, parabens, bisphenol A and triclosan in Swedish mothers and their children. Environment International, 73, 323-333. https://doi.org/10.1016/j.envint.2014.08.014

Lee, C., Zhang, G., \& Edwards, M. (2012). Ordinary least squares estimation of parameters in exploratory factor analysis with ordinal data. Multivariate Behavioral Research, 47(2), 314-339.

Leip, A., Billen, G., Garnier, J., Grizzetti, B., Lassaletta, L., Reis, S., et al. (2015). Impacts of European livestock production: Nitrogen, sulphur, phosphorus and greenhouse gas emissions, land-use, water eutrophication and biodiversity. Environmental Research Letters, 10(11), 115004. https://doi.org/10. $1088 / 1748-9326 / 10 / 11 / 115004$

Lence, S. (2009). Joint estimation of risk preferences and technology: Flexible utility or futility? American Journal of Agricultural Economics, 91(3), 581-598.

Li, M., Shi, J., Luo, J., Long, Q., Yang, Q., Ouyang, Y., et al. (2020). Diet quality among women with previous gestational diabetes mellitus in rural areas of Hunan Province. International Journal of Environmental Research and Public Health, 17(16), 1-16. https://doi.org/10.3390/ijerph17165942

Li, X. (2016). Environmental exposure science: A new inter discipline. Foreign MedicalScience Section of Medgeography, 37(2), 81-84.

Lin, B., \& Benjamin, I. N. (2018). Causal relationships between energy consumption, foreign direct investment and economic growth for MINT: Evidence from panel dynamic ordinary least square models. Journal of Cleaner Production, 197, 708-720. https://doi.org/10.1016/j.jclepro.2018.06.152

Lonappan, L., Rouissi, T., Das, R., Brar, S., Ramirez, A., Verma, M., \& Valero, J. (2016). Adsorption of methylene blue on biochar microparticles derived from different waste materials. Waste Management, 49, 537-544.

Lopes, L. (1986). Between hope and fear: The psychology of risk. Advances in Experimental Social Psychology, 20(3), 255-295.

Maydeu-Olivares, A., Shi, D., \& Rosseel, Y. (2019). Instrumental variables two-stage least squares (2SLS) versus maximum likelihood structural equation modeling of causal effects in linear regression models. Structural Equation Modeling, 26(6), 876-892. https://doi.org/10.1080/10705511.2019.1607740

Menapace, L., Colson, G., \& Raffaelli, R. (2016). A comparison of hypothetical risk attitude elicitation instruments for explaining farmer crop insurance purchases. European Review of Agricultural Economics, 43(1), 113-135. https://doi.org/10.1093/erae/jbv013

Meraner, M., \& Finger, R. (2019). Risk perceptions, preferences and management strategies: Evidence from a case study using German livestock farmers. Journal of Risk Research, 22(1), 110-135. https://doi. org/10.1080/13669877.2017.1351476

Meza, B. P. L., Chatrathi, M., Pollack, C. E., Levine, D. M., Latkin, C. A., Clark, J. M., et al. (2020). Social network factors and cardiovascular health among baltimore public housing residents. Preventive Medicine Reports, 20(8), 101192. https://doi.org/10.1016/j.pmedr.2020.101192 
Mhlongo, E. M., Lutge, E., \& Adepeju, L. (2020). The roles, responsibilities and perceptions of community health workers and ward-based primary health care outreach teams: A scoping review. Global Health Action, 13(1), 1806526. https://doi.org/10.1080/16549716.2020.1806526

Molnár, M., \& Fraser, D. (2020). Protecting farm animal welfare during intensification: Farmer perceptions of economic and regulatory pressures. Animal Welfare, 29(2), 133-141. https://doi.org/10.7120/ 09627286.29.2.133

Nath, P., Byrd, K., Das, J., Sharmin, A., Amin, R., Rahman, M., \& Mridha, M. (2019). Beliefs, practices, and advice received on nutrition and health during pregnancy: Qualitative reports from pregnant women in rural Bangladesh(P10-021-19). Current Developments in Nutrition, 3(2), 773. https://doi. org/10.1093/cdn/nzz034.p10-021-19

National Bureau of Statistics of China. (2019). 693.82 million pigs were slaughtered and a decrease of $12 \%$ in 2018. Modern Animal Husbandry and Veterinary, 2, 60.

Neethirajan, S. (2020). Transforming the adaptation physiology of farm animals through sensors. Animals, 10(9), 1-24. https://doi.org/10.3390/ani10091512

Nie, X., Zhou, J., Cheng, P., \& Wang, H. (2021). Exploring the differences between coastal farmers' subjective and objective risk preferences in China using an agent-based model. Journal of Rural Studies, 82(100), 417-429. https://doi.org/10.1016/j.jrurstud.2021.01.037

Oskar, S., \& Stingone, J. A. (2020). Machine learning within studies of early-life environmental exposures and child health: Review of the curreht literature and discussion of next steps. Current Environmental Health Reports, 7(3), 170-184. https://doi.org/10.1007/s40572-020-00282-5

Perkins, J. E., Rahman, A. E., Siddique, A. B., Mazumder, T., Haider, M. R., \& El Arifeen, S. (2019). Awareness and perceptions of women regarding human rights related to maternal health in rural Bangladesh. Journal of Global Health, 9(1), 1-13. https://doi.org/10.7189/JOGH.09.010415

Poom, A., Willberg, E., \& Toivonen, T. (2021). Environmental exposure during travel: A research review and suggestions forward. Health and Place, 70(4), 102584. https://doi.org/10.1016/j.healthplace. 2021.102584

Post, P. M., Hogerwerf, L., Bokkers, E. A. M., Baumann, B., Fischer, P., Rutledge-Jonker, S., et al. (2020). Effects of Dutch livestock production on human health and the environment. Science of the Total Environment, 737, 139702. https://doi.org/10.1016/j.scitotenv.2020.139702

Qiu, Z., Si, R., \& Zhang, S. (2015). Experimental economic measurement of risk preference.E conomic. Issues, 32(3), 12-24.

Qiu, H., Su, L., Zhang, Y., \& Tang, J. (2020a). Risk preference, risk perception and farmers' adoption of conservation tillage technology. China Rural Economy, 4(7), 59-79.

Qiu, H. G., Luan, H., \& Li, J. (2014). The impact of risk aversion on farmer households'excessive fertilizer application. China Rural Economy, 3, 85-96.

Qiu, H. G., Su, L., Zhang, Y., \& Tang, J. (2020b). Risk preference, risk perception and farmers'adoption of conservation tillage. China Rural Economics, 7, 59-79.

Rappaport, S. (2011). Implications of the exposome for exposure science. Journal of Exposure Science and Environmental Epidemiology, 21(1), 5-9.

Rappaport, S., \& Smith, M. (2010). Environment and disease risks. Science, 330, 460-461.

Roumasset, J. (1976). Rice and risk: Decision-making among low-income farmers. North-Holland Press.

Santos, S., Maitre, L., Warembourg, C., Agier, L., Richiardi, L., Basagaña, X., \& Vrijheid, M. (2020). Applying the exposome concept in birth cohort research: A review of statistical approaches. European Journal of Epidemiology, 35(3), 193-204. https://doi.org/10.1007/s10654-020-00625-4

Sarwosri, A. W., \& Mußhoff, O. (2020). Are Risk Attitudes and Time Preferences Crucial Factors for Crop Diversification by Smallholder Farmers? Journal of International Development, 32(6), 922-942. https://doi.org/10.1002/jid.3483

Scheel, J. R., Parker, S., Hippe, D. S., Patrick, D. L., Nakigudde, G., Anderson, B. O., et al. (2019). Role of family obligation stress on ugandan women's participation in preventive breast health. The Oncologist, 24(5), 624-631. https://doi.org/10.1634/theoncologist.2017-0553

Scott, J. (1997). The Moral Economy of the Peasant: Rebellion and Subsistence in Southeast Asia. Yale University Press.

Senapati, R., Nayak, B., Kar, S. K., \& Dwibedi, B. (2017). HPV Genotypes distribution in Indian women with and without cervical carcinoma: Implication for HPV vaccination program in Odisha Eastern India. BMC Infectious Diseases, 17(1), 1-10. https://doi.org/10.1186/s12879-016-2136-4

Shaffer, R. M., Smith, M. N., \& Faustman, E. M. (2017). Developing the regulatory utility of the exposome: Mapping exposures for risk assessment through lifestage exposome snapshots (LEnS). Environmental Health Perspectives, 125(8), 1-8. https://doi.org/10.1289/EHP1250 
Sharifzadeh, M., Abdollahzadeh, G., Damalas, C., Rezaei, R., \& Ahmadyousefi, M. (2019). Determinants of pesticide safety behavior among Iranian rice farmers. Science of the Total Environment Total Environ, 651, 2953-2960.

Si, R., Wang, M., Lu, Q., \& Zhang, S. (2020). Assessing impact of risk perception and environmental regulation on household carcass waste recycling behaviour in China. Waste Management and Research, 38(5), 528-536. https://doi.org/10.1177/0734242X19878496

Sinclair, K., Ahmadigheidari, D., Dallmann, D., Miller, M., \& Melgar-Quiñonez, H. (2019). Rural women: Most likely to experience food insecurity and poor health in low-and middle-income countries. Global Food Security, 23(8), 104-115. https://doi.org/10.1016/j.gfs.2019.04.006

Slovic, P. (1987). Perception of risk. Science, 236(4799), 280-285.

Sogno, P., Traidl-ho, C., \& Kuenzer, C. (2020). Non-communicable disease research: A review. Remote Sensing, 12(16), 1-34.

Song, Y., Zhang, J., \& Zhang, X. (2020). Cultural or institutional? contextual effects on domestic violence against women in rural China. Journal of Family Violence, 24(9), 1-13. https://doi.org/10. 1007/s10896-020-00198-6

Spielman, D. J., Davis, K., Negash, M., \& Ayele, G. (2011). Rural innovation systems and networks: Findings from a study of Ethiopian smallholders. Agriculture and Human Values, 28(2), 195-212. https://doi.org/10.1007/s10460-010-9273-y

Su, K., Wei, D. Z., \& Lin, W. X. (2020). Influencing factors and spatial patterns of energy-related carbon emissions at the city-scale in Fujian province, Southeastern China. Journal of Cleaner Production, 244, 118840. https://doi.org/10.1016/j.jclepro.2019.118840

Sugiyama, T., Carver, A., \& Koohsari, M. (2018). Advantages of public green spaces in enhancing population health. Landscape and Urban Planning, 178, 12-17.

Sun, R., Zhang, X. X., Guo, X., Wang, D., \& Chu, H. (2015). Bacterial diversity in soils subjected to long-term chemical fertilization can be more stably maintained with the addition of livestock manure than wheat straw. Soil Biology and Biochemistry, 88, 9-18. https://doi.org/10.1016/j.soilb io.2015.05.007

Tong, Q., Swallow, B., Zhang, L., \& Zhang, J. (2019). The roles of risk aversion and climate-smart agriculture in climate risk management: Evidence from rice production in the Jianghan Plain China. Clim. Risk Management, 26, 1-13.

Turvey, C., He, G., \& Jiujie, M. (2012). Farm credit and credit demand elasticities in Shaanxi and Gansu. China Economic Review, 23(4), 1020-1035.

Verburg, P. H., \& Overmars, K. P. (2009). Combining top-down and bottom-up dynamics in land use modeling: Exploring the future of abandoned farmlands in Europe with the Dyna-CLUE model. Landscape Ecology, 24(9), 1167-1181. https://doi.org/10.1007/s10980-009-9355-7

Wang, H., Qiao, J., \& Li, B. (2019). The willingness of farmers to participate in the construction of standardized farms and its influencing factors_-Based on the survey data of pig farmers in four provinces. China Rural Observation, 4, 111-127.

Wang, J., Yang, C., Ma, W., \& Tang, J. (2020). Risk preference, trust, and willingness-to-accept subsidies for pro-environmental production: An investigation of hog farmers in China. Environmental Economics and Policy Studies, 22(3), 405-431. https://doi.org/10.1007/s10018-020-00262-x

Weber, E., \& Milliman, R. (1997). Perceived risk attitudes: Relating risk perceptions to risky choice. Management Science, 43, 123-144.

Więckol-Ryk, A., Białecka, B., \& Thomas, M. (2020). Effect of green oxidizing agent on inhibition of escherichia coli present in livestock Wastes. Water, Air, and Soil Pollution, 231(9), 1-16. https:// doi.org/10.1007/s11270-020-04824-3

Wild, C. (2005). Complementing the genome with an "exposome": The outstanding challenge of environmental exposure measurement in molecular epidemiology. Cancer Epidemiology Biomarkers and Prevention, 14(8), 1847-1850. https://doi.org/10.1158/1055-9965.EPI-05-0456

Wild, C. (2012). The exposome: From concept to utility. International Journal of Epidemiology, 41(1), 24-32.

Won, S., Yoon, Y., Hamid, M. M. A., Reza, A., Shim, S., Kim, S., et al. (2020). Estimation of greenhouse gas emission from hanwoo (Korean native cattle) manure management systems. Atmosphere. https://doi.org/10.3390/ATMOS11080845

Xu, L., Jin, W., \& Chen, K. (2020). Risk appetite, information acquisition and pollution exposure behavior of pig breeding: Based on an empirical analysis of 1489 pig breeders in 8 provinces. China Rural Observation, 4, 129-144.

$\mathrm{Xu}, \mathrm{X} ., \mathrm{Xu}, \mathrm{C}$. , \& Li, C. (2018). The influence of relationship networks on farmers'forest land inflow behavior-Based on survey data in Zhejiang Province. China Rural Economy, 9, 62-78. 
Yilmaz, O., Savas, T., Ertugrul, M., \& Wilson, R. (2013). The domestic livestock resources of Turkey: Inventory of pigeon groups and breeds with notes on breeder organizations. World's Poultry Science Journal, 69(2), 265-278.

Yue, H., Hu, J., Li, L., \& Liu, C. (2019). Determination of the amount of manure produced by pigs at different stages of feeding test report. Yunnan Animal Husbandry and Veterinary Medicine, 4, 1-4.

Zhang, J., Mishra, A., \& Zhu, P. (2020). Land rental markets and labor productivity: Evidence from rural China. Canadian Journal of Agricultural Economics, 3, 1-23. https://doi.org/10.1111/cjag.12247

Zhang, X., Chen, X., \& Zhang, X. (2018). The impact of exposure to air pollution on cognitive performance. Proceedings of the National Academy of Sciences of the United States of America, 115(37), 9193-9197.

Zhao, J., Liu, T., \& Wei, J. (2017). Does the risk attitude affect the safety of apple production? Based on the experimental data of farmers in the main apple producing areas. Agricultural Technology and Economy, 4, 95-105.

Zhou, Z., Liu, J., Zeng, H., Zhang, T., \& Chen, X. (2020). How does soil pollution risk perception affect farmers' pro-environmental behavior? The role of income level. Journal of Environmental Management, 270(6), 110806. https://doi.org/10.1016/j.jenvman.2020.110806

Zhu, Z., Huang, C., \& Xu, Z. (2016). Analysis of the impact of forest farmers' risk preference on carbon sink supply willingness in southern collective forest areas: An experimental case of risk preference in Zhejiang Province. Resources Science, 38(3), 565-575.

Publisher's Note Springer Nature remains neutral with regard to jurisdictional claims in published maps and institutional affiliations. 